DOI: $10.46523 /$ jarssc.05.01.07

Multidisciplinary, Open Access

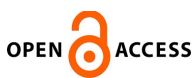

\title{
Relationship Between Sleep Pattern and Affective States Among College Going Females
}

\author{
Akankshi Srivastava \\ Assistant Professor, Department of Psychology, Vasanta College for Women, Varanasi \\ E-mail: dr.akankshi.s@gmail.com
}

\begin{abstract}
Sleep is recognized as one of the basic physiological needs. Inadequate or poor quality of sleep have been associated with several emotional and behavioral problems in daily life. Disturbance in sleeping patterns and circadian rhythms have also been implicated in serious psychological conditions such as depression, anxiety and stress.

The present study aimed to examine the relationship between pattern of sleep and the affective state experienced upon waking. Pattern of sleep was defined in terms of three criteria: 1 . Number of hours of sleep, 2. Quality of sleep and 3. activity engaged in before sleeping. Both dimensions of affect: positive and negative affect were examined independently.
\end{abstract}

The sample consisted of 110 college going females (mean age=21). The Positive and Negative Affect Schedule (PANAS X) by Watson \&Clark (1994) was used to assess the affective state of participants within one hour of waking up. A Sleep Pattern Questionnaire was developed by the researcher to record the different criteria of the participants sleep the previous night. The data was analyzed using correlation and percentage analysis.

The results of the study suggested that duration of sleep has no relation with the affective state in which one wakes up as the correlation coefficients between number of hours of sleep and both positive affect $(0.13)$ and negative affect $(-0.01)$ were not significant. Quality of sleep showed a strong association to both positive and negative affect. Greater percentage of participants who reported having continuous, deep or satisfactory sleep reported high positive affect in comparison to participants who reported having irregular, disturbed or incomplete sleep. Conversely, greater percentage of participants who reported having irregular, disturbed or incomplete sleep reported high negative affect than those who had continuous, deep or satisfactory sleep. Having indulged in different types of activities before sleeping did not show any difference in the affective state in which participants woke up. 
Journal of Advance Research in Science and Social Science (JARSSC)

Official Publication of Indian Mental Health \& Research Centre
ISSN: $2582-2004$

Volume 05, Issue 01

DOI: $10.46523 /$ jarssc.05.01.07

Multidisciplinary, Open Access

The findings of the study are discussed comprehensively, in light of existing theories and research in the area.

Keywords: sleep, positive affect, negative affect, quality of sleep, sleep disturbances

\section{INTRODUCTION}

The role of sleep in mental health has been long recognized. Even lay persons know that insufficient and disturbed sleep can cause emotional problems. More formal research has suggested that not only is sleep a symptom of many psychological disorders, rather, it is one of the causes of several serious mental health problems(Pandina, Garibaldi, Revicki, Kleinman, Turkoz, Kujawa \& Mahmoud, 2010; Zimmermann, Clouth, Elosge, Heurich, Schneider, Wilhelm \& Wolfrath, 2013). Disturbance in sleep cycles and circadian rhythms is one of the major causal factors implicated in depression, bipolar disorder as well as stress (Fawcett, Scheftner, Fogg, Clark, Young, Hedeker \& Gibbons, 1990; Turvey, Conwell, Jones, Phillips, Simonsick, Pearson \& Wallace, 2002).

Sleep is recognized as one of the physiological needs of the body and deprivation or disturbances in it have been associated with several physical and mental health issues (Foley, Ancoli-Israel, Britz \& Walsh, 2004). This topic has long been of interest for researchers, who have tried to understand the neural underpinnings of why sleep plays such a significant role in determining our physical and mental health (Boonstra, Stins, Daffertshofer \& Beek, 2007; Jones \& Harrison, 2001; Bonnet \& Arand, 2003).

In recent years, with a boost in research focused on positive psychology, attention has also been paid to the role of sleep in influencing the well-being of individuals (Leonard, Fanning, Attwood \& Buckley, 1998; pTotterdell, Reynolds, Parkinson \& Briner, 1994; Johnson \& Macleod, 1973). With changing lifestyles to match the fast pace of life, sleep disturbances and lack of sleep have been observed in many people. With such alarming trends, the effect of sleep deprivation and disturbance has been recognized in various everyday issues. One of them is the role that sleep plays in determining the general affective state of individuals.

Affect is defined as "a person's immediate, physiological response to a stimulus, and it is typically based on an underlying sense of arousal" (Pedrotti, Lopez \& Snyder, 2021). According to Frijda (1999) affect involves the appraisal of any event on two components: the valance (pleasure or pain) and the experience of autonomic arousal. Challenging the 
Journal of Advance Research in Science and Social Science (JARSSC)

Official Publication of Indian Mental Health \& Research Centre
ISSN: $2582-2004$

Volume 05, Issue 01

DOI: $10.46523 /$ jarssc. 05.01 .07

Multidisciplinary, Open Access

historically held notion that positive and negative affect are polar opposites, research in recent years has shown that these are two independent dimensions of affective states and individuals can experience both positive and negative affect together in certain situations (Bradburn, 1969; Watson, 2002; Watson \& Naragon-Gainey, 2014).

The influence of sleep pattern on affect has been studied to some extent. There is literature that has found a moderate relation between duration of sleep and affective state experienced the following day (Totterdell, Reynolds, Parkinson \& Briner, 1994; Johnson \& Macleod, 1973). These studies suggest that extremely short duration of sleep can cause greater negative affect and reduced positive affect the next day.

The quality of sleep, in terms of whether the individual had a deep or irregular and disturbed sleep have also been paid some attention. Sound and satisfactory sleep has been associated with greater positive affect experience and reduction in negative affect, irritability and stress (Triantafillou, Saeb, Lattie, Mohr \& Kording (2019; Blaxton, Bergeman, Whitehead, Braun \& Payne, 2017).

Although attempts have been made to see the effect of several activities done before going to bed on the quality of sleep (Miller, Sargent, Roach, Scanlan, Vincent \& Lastella, 2020; Mindell, Telofski, Wiegand \& Kurtz, 2009), empirical efforts have not been directed towards comparing whether different bed time activities also have different effects on the affective state in which one wakes up.

The present study aimed to examine the relationship between pattern of sleep and the affective state experienced upon waking. Pattern of sleep was defined in terms of three criteria: 1 . Number of hours of sleep, 2. Quality of sleep and 3. Activity engaged in before sleeping. In line with the latest theories of affect, positive and negative affect were examined independently.

The following hypotheses were formulated with regards to the study: 1. Number of hours of sleep will show a direct relationship with positive affect scores. 2. Number of hours of sleep will show an inverse relationship with negative affect scores. 3. Greater percentage of people reporting continuous, deep or satisfactory sleep will score highly on positive affect than percentage of people reporting irregular, disturbed or incomplete sleep. 4. Greater percentage of people reporting irregular, disturbed or incomplete sleep will score highly on negative affect 
Journal of Advance Research in Science and Social Science (JARSSC)

Official Publication of Indian Mental Health \& Research Centre
ISSN: $2582-2004$

Volume 05, Issue 01

DOI: $10.46523 /$ jarssc.05.01.07

Multidisciplinary, Open Access

than percentage of people reporting continuous, deep or satisfactory sleep. 5. Indulging in different types of activities prior to sleeping will show varied percentage of people who show high scores on positive and negative affect.

\section{METHOD}

\section{Participants}

The study participants included 110 college going females. The mean age of participants was 21 years. All the participants were students of under graduate or post graduate programs.

\section{Tools}

Sleep Pattern Questionnaire: A short questionnaire was developed by the researcher for the purpose of the present study, to gather information regarding the sleep pattern of participants. The questionnaire consisted of 4 questions which inquired about the time at which the participant went to sleep the previous night, the time at which they woke up in the morning, the quality of sleep (participants had to select the words that best described their sleep from a list of six adjectives: continuous, irregular, deep, disturbed, satisfactory and incomplete), and the activity they indulged in just before going to sleep the previous night (open ended).

Positive and Negative Affect Schedule: The PANAS-X (Watson \&Clark, 1994) is a 20 item scale to measure the current affective state of individuals. The scale measures both "negative" (unpleasant) and "positive" (pleasant) valence. The content of negative affective states can be described best as general distress, whereas positive affect includes joviality, self-assurance, and attentiveness. The scale consists of a number of words that describe different feelings and emotions. The respondent has to read each item and then indicate to what extent they feel this emotion at that moment on a five point rating scale.

\section{Administration}

The participants were contacted through social networks and they were asked to fill in an online form in which they had to mention their demographic details, provide data about their sleep pattern as well as respond to the Positive And Negative Affect Schedule. Participants had to respond to the form within one hour of waking up in the morning. The data provided by the 
Journal of Advance Research in Science and Social Science (JARSSC)

Official Publication of Indian Mental Health \& Research Centre
ISSN: $2582-2004$

Volume 05, Issue 01

DOI: $10.46523 /$ jarssc. 05.01 .07

Multidisciplinary, Open Access

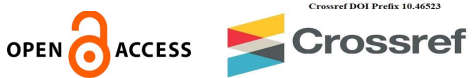

participants was screened to exclude data that did not meet the inclusion criteria for participants. On the basis of this data, analysis was done on several levels.

\section{Analysis}

The relationship between sleep patterns and affective state upon waking up was analyzed on three levels. Pearson Product Moment correlation was computed between number of hours of sleep as reported by participants and the total scores of both positive and negative affect independently. Percentage analysis was done on the data of quality of sleep. The six markers of quality of sleep were compared on the basis of the percentage of people, who selected different markers, who scored a high positive affect score and a high negative affect score (total scores above 30 ). To examine the relation between activity indulged in prior to bed time and affective state upon waking up, percentage analysis was done comparing the percentage of people who scored a high positive and negative affect score (total scores above 30) after reporting engaging in different activities preceding sleep. As the concept of positive and negative affect were theoretically different, their scores were analyzed separately at all three levels.

\section{RESULTS}

The present study was conducted to examine the relationship between pattern of sleep with affective states upon waking up. Pattern of sleep was examined using three independent criteria: duration of sleep, quality of sleep and activity done prior to sleep. Duration of sleep was measured by the number of hours of sleep during the night. Quality of sleep was assessed through self-report of participants about the continuity, completeness, etc. with regards to their night's sleep. Both positive and negative affect were taken as criterion variables.

The correlation analysis of number of hours of sleep and positive and negative affect yielded very low correlation coefficients. The correlation coefficient between number of hours and positive affect was 0.13 which is a very low positive correlation (not significant at the 0.05 level). The correlation coefficient between number of hours and negative affect upon waking up was -0.01 which indicates no correlation between the two variables (not significant at the 0.05 level). 
Journal of Advance Research in Science and Social Science (JARSSC)

Official Publication of Indian Mental Health \& Research Centre
ISSN: $2582-2004$

Volume 05, Issue 01

DOI: $10.46523 /$ jarssc.05.01.07

Multidisciplinary, Open Access

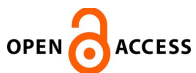

The results indicate that participant's affective states upon waking up had no relation to the amount of sleep they had the previous night. Thus, the first two hypotheses: 'Number of hours of sleep will show a direct relationship with positive affect scores.' And 'Number of hours of sleep will show an inverse relationship with negative affect scores.' Do not find support in the present study.

Quality of sleep was examined using three markers: continuous or irregular, deep or disturbed, and satisfactory or incomplete sleep. Participants chose from these six adjectives the ones that best described their sleep the previous night. Percentage analysis of the data was done to examine whether people reporting specific quality markers were more or less likely to experience positive or negative affect upon waking up (see figure 1 and figure 2).

The results revealed that there was quite a large difference in the percentage of people who experienced highly positive affect after continuous sleep (72\%) and those who experienced highly positive affect after an irregular sleep (56\%). Further, percentage of people who experienced highly negative affect after a continuous sleep (12\%) was much less than the percentage of people who experienced highly negative affect after an irregular sleep (21\%).

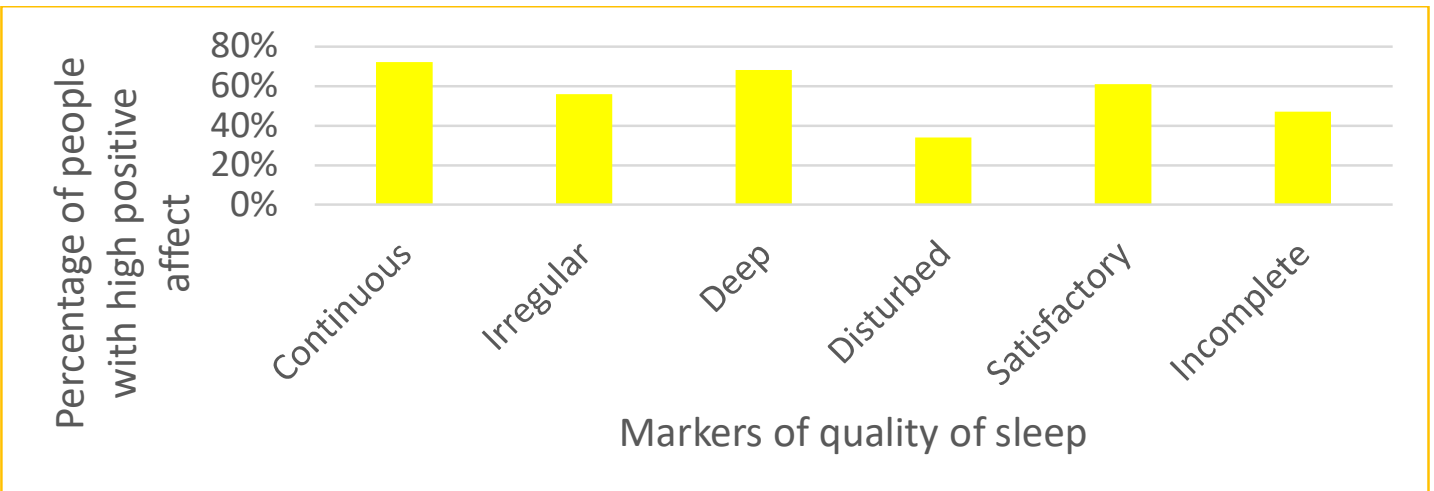

Figure 1: Percentage of people who reported highly positive affect with different quality of sleep

An even larger difference was observed in the percentage of people who experienced a high positive affect post deep sleep (68\%) and those who experienced high positive affect after a disturbed sleep (34\%). A high negative affect was reported by $59 \%$ of people who had disturbed 
Journal of Advance Research in Science and Social Science (JARSSC)

Official Publication of Indian Mental Health \& Research Centre
ISSN: 2582-2004

Volume 05, Issue 01

DOI: $10.46523 /$ jarssc.05.01.07

Multidisciplinary, Open Access

sleep while only $13 \%$ of people who had a deep sleep reported experiencing high negative affect upon waking up.

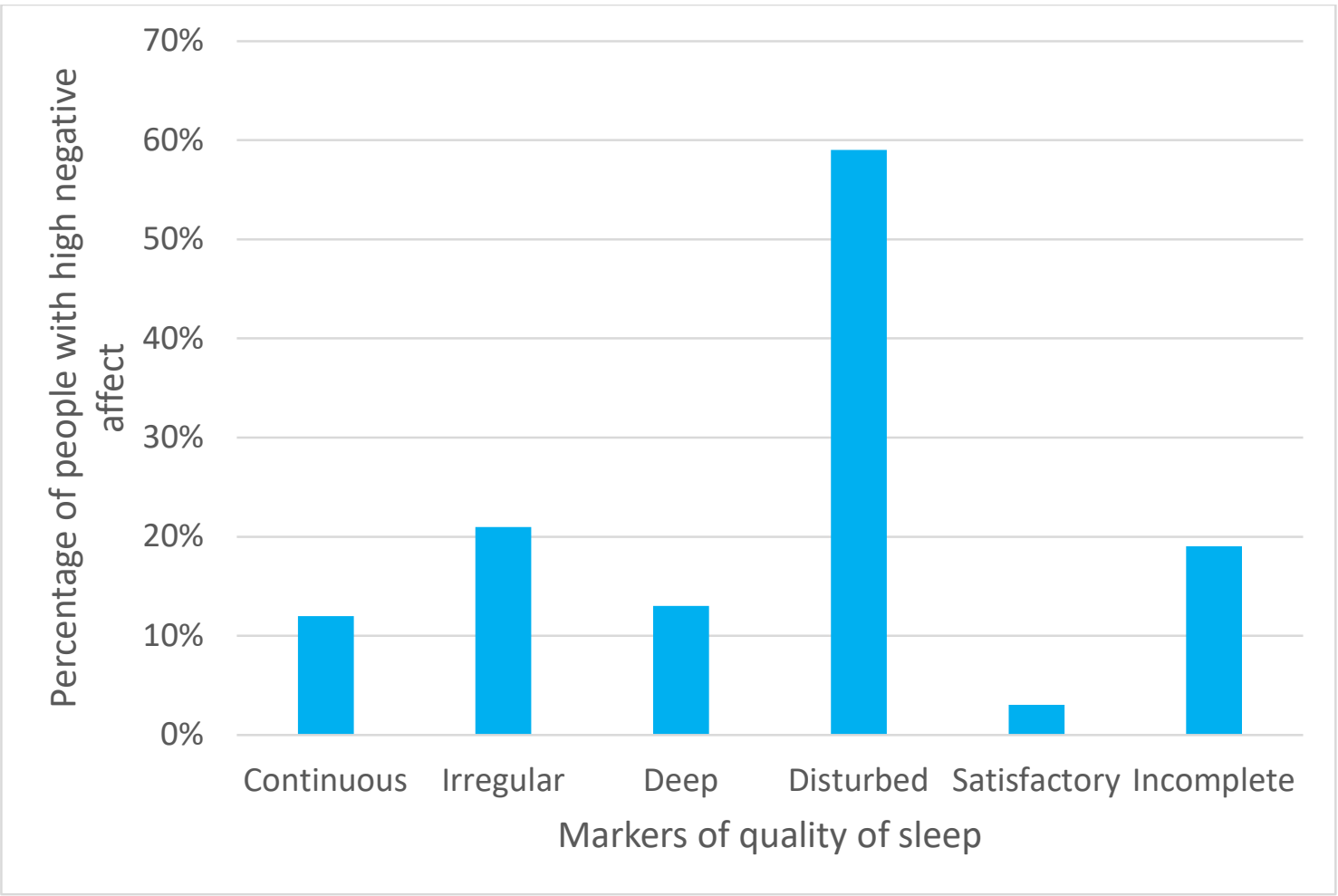

Figure 2: Percentage of people who reported highly negative affect with different quality of sleep.

With regards to level of satisfaction with sleep, $61 \%$ of people who reported being satisfied with their sleep reported a high positive affect, while a mere $3 \%$ of people who were satisfied with their sleep reported a high negative affect. Out of the people who experienced incomplete sleep, $47 \%$ reported high positive affect, which is much less than the percentage of people who were satisfied with their sleep. High negative affect was reported by $19 \%$ of people who experienced incomplete sleep which is much higher than percentage of people who experienced satisfactory sleep.

Thus, the third and fourth hypotheses: 'Greater percentage of people reporting continuous, deep or satisfactory sleep will score highly on positive affect than percentage of people reporting irregular, disturbed or incomplete sleep.' And 'Greater percentage of people reporting irregular, disturbed or incomplete sleep will score highly on negative affect than percentage of 
Journal of Advance Research in Science and Social Science (JARSSC)

Official Publication of Indian Mental Health \& Research Centre
ISSN: $2582-2004$

Volume 05, Issue 01

DOI: $10.46523 /$ jarssc.05.01.07 Multidisciplinary, Open Access

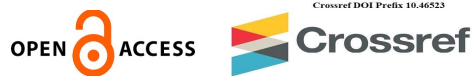

people reporting continuous, deep or satisfactory sleep.' Both find support in the results of the present study.

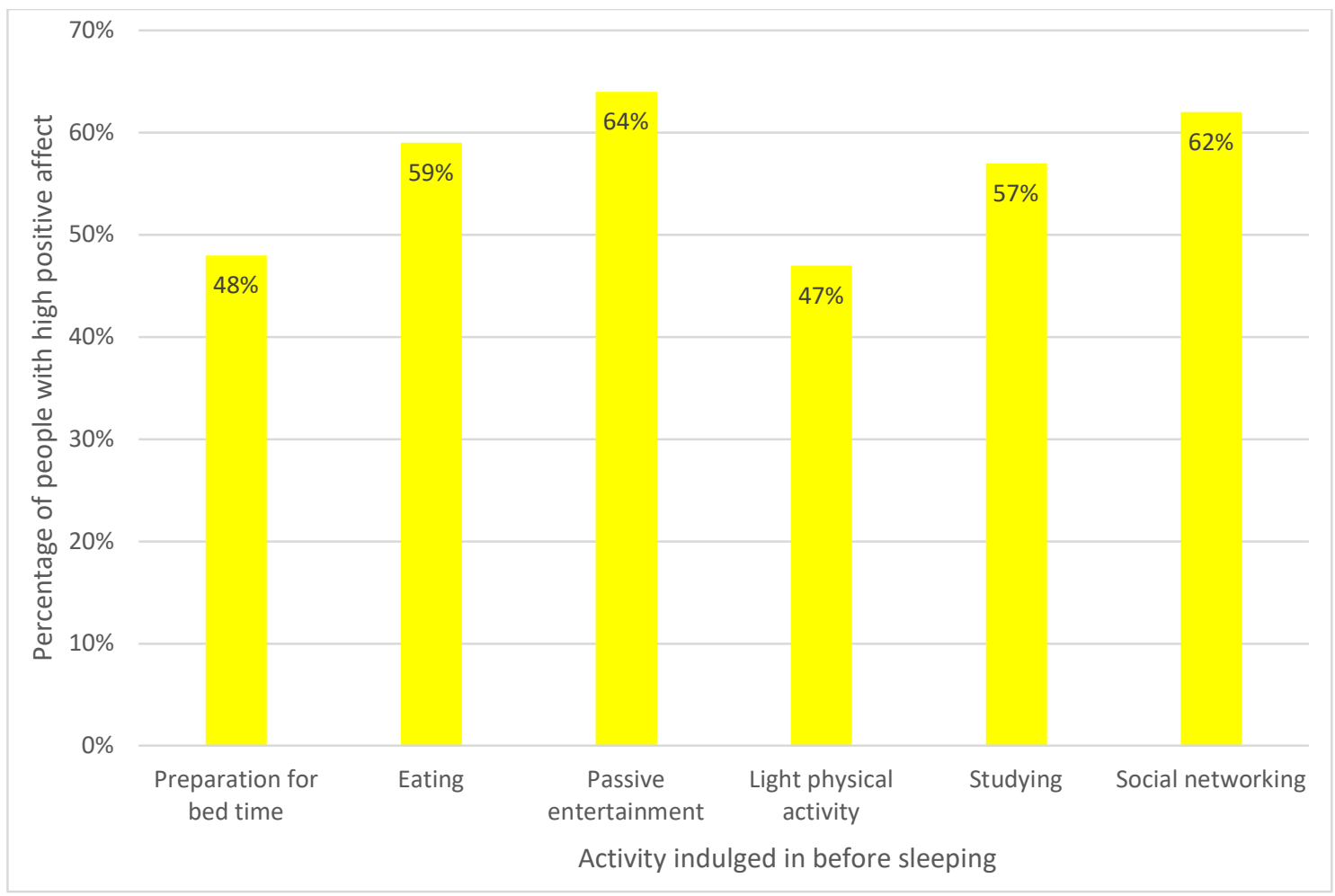

Figure 3: Percentage of people who reported highly positive affect with different activities indulged in before sleeping.

In order to analyse the data with regards to the activity indulged in prior to bed time, the responses were clubbed into six categories: preparation for bed time (such as arranging the bed, changing clothes, brushing teeth etc.), eating, passive entertainment (like reading books, listening to music or watching movies), light physical activity (such as walking), studying, and social networking (such as chatting with friends on phone or browsing social media websites). Upon analysing this data, people who engaged in different activities before sleeping did not show much difference in their experience of positive and negative affect (see figure 3 and figure 4). 
DOI: $10.46523 /$ jarssc.05.01.07 Multidisciplinary, Open Access

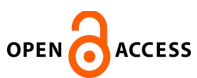
Crossref

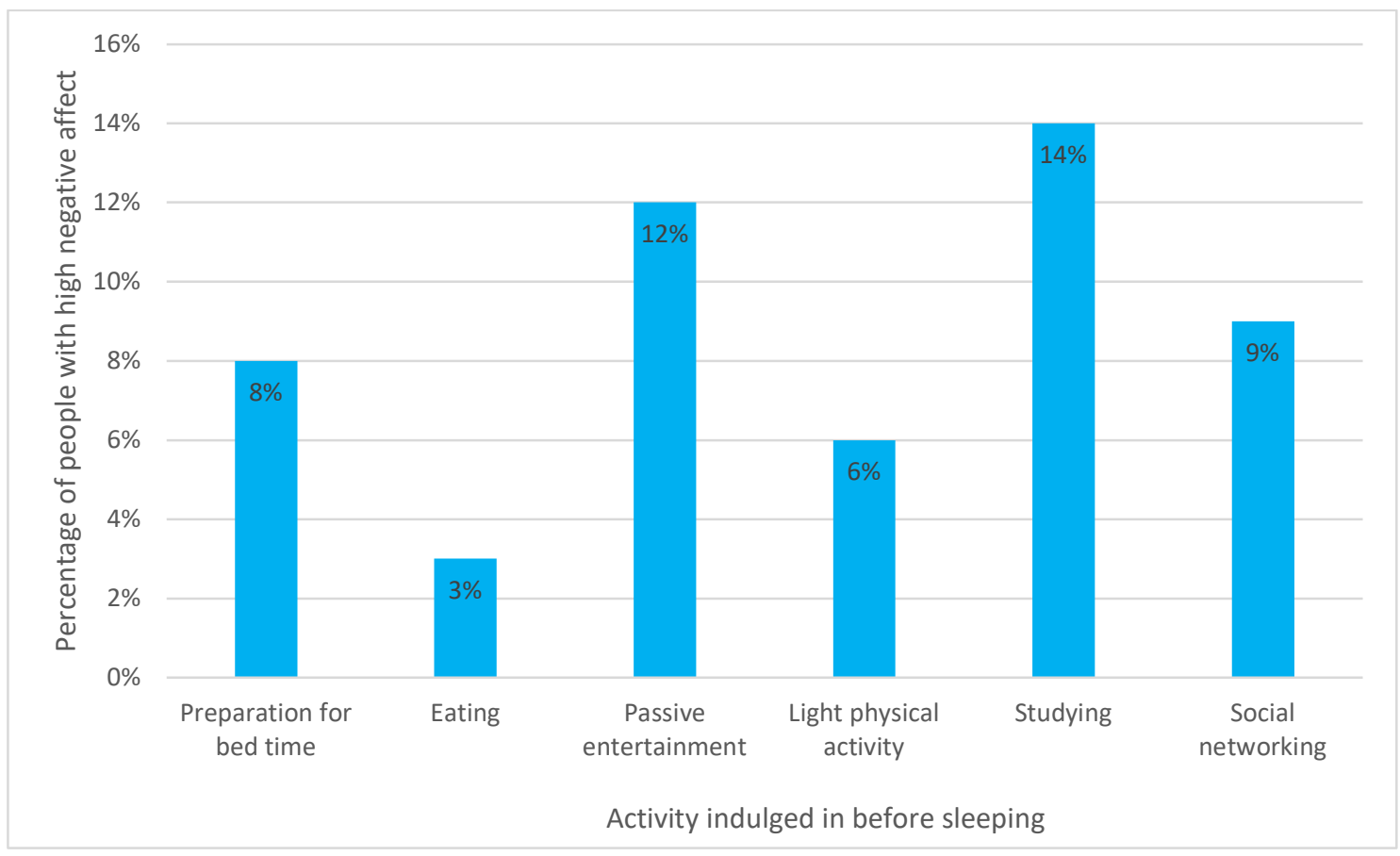

Figure 4: Percentage of people who reported highly negative affect with different activities indulged in before sleeping.

Thus, the fifth hypothesis: 'Indulging in different types of activities prior to sleeping will show varied percentage of people who show high scores on positive and negative affect.' Does not find sufficient support in the present research.

\section{DISCUSSION}

The present study was conducted to examine the relationship between sleep patterns and affective state upon waking up. Three criteria were considered with regards to sleep patterns: number of hours of sleep, quality of sleep and activity indulged in before sleeping. Both positive and negative affect upon waking were analysed as theoretically they are seen as two independent dimensions rather than as the polar ends of a single continuum. It was hypothesized that number of hours of sleep will show a direct relationship with positive affect scores and an inverse relationship with negative affect scores. With regards to quality of sleep, it was hypothesized that greater percentage of people reporting continuous, deep and satisfactory sleep will score highly on positive affect while greater percentage of people reporting irregular, disturbed or incomplete sleep will score highly on negative affect. Finally, 
Journal of Advance Research in Science and Social Science (JARSSC)

Official Publication of Indian Mental Health \& Research Centre
ISSN: $2582-2004$

Volume 05, Issue 01

DOI: $10.46523 /$ jarssc. 05.01 .07

Multidisciplinary, Open Access

it was hypothesized that indulging in different types of activities prior to sleeping will show varied percentage of people who show high scores on positive and negative affect.

The results did not support the first two hypotheses with regards to the relationship between number of hours of sleep and positive and negative affect upon waking. The correlation coefficients for both positive affect (0.13) and negative affect (-0.01) were too small to indicate the existence of a significant relationship between quantity of sleep and affective state at waking. Thus, the results of the present study suggest that the number of hours one sleeps for has no relation to the affective state the person wakes up in.

Although existing literature hints at a connection between amount of sleep and mood states, the association isn't as strong as that of other variables. Totterdell, Reynolds, Parkinson \& Briner (1994) reported that time of onset of sleep was a better predictor of mood states the following day than amount of sleep. Johnson \& Macleod (1973), in an experimental study saw that sleep reduction affected mood states only when duration of sleep was reduced below 5 hours, causing irritability and negative affect in individuals. It should be noted here that the average duration of sleep reported by participants of the present study was 7.2 hours. Thus, the relationship between number of hours and affective states was not significant.

The results pertaining to quality of sleep were more eye opening, with participants who experienced continuous, deep or satisfactory sleep showing significantly greater incidence of highly positive affect upon waking than those who experienced irregular, disturbed or incomplete sleep. Further, the incidence of high negative affect was much larger in participants who reported irregular, disturbed or incomplete sleep than those who experienced continuous, deep or satisfactory sleep. Thus, the results clearly suggest that affective states at waking are associated with the quality of sleep.

Triantafillou, Saeb, Lattie, Mohr \& Kording (2019) reported similar findings, suggesting that sleep disturbance affects mood states and this effect is much stronger than the effect of previous days mood on the mood next morning. They also found that effects of quality of sleep on mood were greater for controls than people who suffer from anxiety or depression.

Blaxton, Bergeman, Whitehead, Braun \& Payne (2017)Also reported a strong link between sleep quality and daily positive and negative affect. They found that participants who reported 
Journal of Advance Research in Science and Social Science (JARSSC)

Official Publication of Indian Mental Health \& Research Centre
ISSN: $2582-2004$

Volume 05, Issue 01

DOI: $10.46523 /$ jarssc.05.01.07

Multidisciplinary, Open Access

better quality of sleep showed increased positive affect and decreased negative affect. Their findings also showed that better sleep quality and positive affect followed by it acted as a buffer against stress.

Sleep disturbance and dissatisfaction with sleep have also been implicated in serious mood disorders, such as major depression (Cuijpers, Beekman, Smit \& Deeg, 2006; Hatzinger, Hemmeter, Brand, Ising \& Holsboer-Trachsler, 2004; Lustberg and Reynolds, 2000)

The third criteria failed to reveal any major differences in the positive and negative affect of people who indulged in varied activities prior to sleeping. Thus, the hypothesis formulated with regards to this criteria was rejected by the results of the present study.

Existing research does show links between different types of activity with better quality of sleep. In a study, Miller, Sargent, Roach, Scanlan, Vincent \& Lastella (2020) found that moderate physical activity predicted better sleep quality in adult males. : He, Tu, Xiao, Su \& Tang (2020) found that reducing use of mobile phones close to bed time significantly improved sleep quality among young adults. Mindell, Telofski, Wiegand \& Kurtz (2009) in a study on young children reported that following a fixed bed time routine was linked to reduction in sleep disturbances.

However, there is a paucity of research linking bed time activity to the affective state upon waking. In light of the findings of the present study, it can be concluded that although the activity engaged in close to bed time influences the sleep quality, no direct link exists between bed time activity and the mood in which one wakes up.

In conclusion, the present study made an effort to understand the relationship between sleep pattern and positive and negative affect as experienced upon waking. the findings suggest that quality of sleep plays a significant role in determining the affective state in which one wakes up. Duration of sleep and the activity indulged in before sleeping do not show any strong link to the affect experienced the following morning.

\section{LIMITATIONS}

The study was conducted only on female participants from a small age bracket, thus, the results should be generalized to other groups only with caution. Further, the data collected was of only 
Journal of Advance Research in Science and Social Science (JARSSC)

Official Publication of Indian Mental Health \& Research Centre

DOI: $10.46523 /$ jarssc. 05.01 .07

Multidisciplinary, Open Access
ISSN: $2582-2004$

Volume 05, Issue 01

a single night's sleep. Analysing data on sleep patterns and affective states from several days could provide better insight into this relationship.

\section{REFERENCES}

Blaxton, J. M., Bergeman, C. S., Whitehead, B. R., Braun, M. E., \& Payne, J. D. (2017). Relationships among nightly sleep quality, daily stress, and daily affect. J Gerontol B Psychol Sci Soc Sci, 72(3), 363-372. doi: 10.1093/geronb/gbv060.

Bonnet, M. H., \& Arand, D. L. (2003) Clinical effects of sleep fragmentation versus sleep deprivation. Sleep Med. Rev., 7, 297-310.

Boonstra, T. W., Stins, J. F., Daffertshofer, A., \& Beek, P. J. (2007). Effects of sleep deprivation on neural functioning: an integrative review. Cellular and molecular life sciences : CMLS, 64(7-8), 934-946. https://doi.org/10.1007/s00018-007-6457-8.

Bradburn, N. M. (1969). The structure of psychological well-being. Chicago: Aldine.

Cuijpers, P., Beekman, A., Smit, F. \& Deeg, D. (2006). Predicting the onset of major depressive disorder and dysthymia in older adults with subthreshold depression: a community based study. Int. J. Geriatr. Psychiatry, 21, 811-818.

Fawcett, J., Scheftner, W. A., Fogg, L., Clark, D. C., Young, M. A., Hedeker, D., \& Gibbons, R. (1990). Time-related predictors of suicide in major affective disorder. Am J Psychiatry, 147(9), 1189-94. doi: 10.1176/ajp.147.9.1189.

Foley, D., Ancoli-Israel, S., Brits, P., \& Walsh, J. (2004). Sleep disturbances and chronic disease in older adults: results of the 2003 National Sleep Foundation Sleep in America Survey. J Psychosom Res, 56(5), 497-502. doi: 10.1016/j.jpsychores.2004.02.010.

Frijda, N. H. (1999). Emotions and hedonic experience. In D. Kahneman, E. Diener, \& N. Schwartz (Eds.), Well-being: The foundations of hedonic psychology (pp. 190-210). New York: Russell Sage.

Hatzinger, M., Hemmeter, U. M., Brand, S., Ising, M., \& Holsboer-Trachsler, E. (2004). Electroencephalographic sleep profiles in treatment course and long-term outcome of major depression: association with DEX/CRH-test response. J. Psychiatr. Res., 38, 453-465. 
Journal of Advance Research in Science and Social Science (JARSSC)

Official Publication of Indian Mental Health \& Research Centre
ISSN: 2582-2004

Volume 05, Issue 01

DOI: $10.46523 /$ jarssc. 05.01 .07

Multidisciplinary, Open Access

He, J. W., Tu Z. H., Xiao, L., Su, T., \& Tang, Y. X. (2020). Effect of restricting bedtime mobile phone use on sleep, arousal, mood, and working memory: A randomized pilot trial. PLoS ONE, 15(2): e0228756. https://doi.org/10.1371/journal.pone.0228756

Johnson, L. C., \& Macleod, W. L. (1973). Sleep and awake behaviour during gradual sleep reduction. Percept Mot Skills, 36, 87-97.

Jones, K. \& Harrison, Y. (2001). Frontal lobe function, sleep loss and fragmented sleep. Sleep Med. Rev, 5, 463-475.

Leonard, C., Fanning, N., Attwood, J. \& Buckley, M. (1998). The effect of fatigue, sleep deprivation and onerous working hours on the physical and mental wellbeing of preregistration house officers. Ir. J. Med. Sci., 167, 22-25.

Lustberg, L. \& Reynolds, C. F. (2000). Depression and insomnia: questions of cause and effect. Sleep Med. Rev., 4, 253-262.

Miller, D. J., Sargent, C., Roach, G.D., Scanlan, A.T., Vincent, G. E., \& Lastella, M. (2020) Moderate-intensity exercise performed in the evening does not impair sleep in healthy males. European Journal of Sport Science, 20(1), 80-89. DOI: 10.1080/17461391.2019.1611934

Mindell, J. A., Telofski, L. S., Wiegand, B., \& Kurtz, E. S. (2009). A nightly bedtime routine: impact on sleep in young children and maternal mood. Sleep, 32(5), 599-606. https://doi.org/10.1093/sleep/32.5.599

Pandina, G. J., Garibaldi, G. M., Revicki, D. A., Kleinman, L., Turkoz, I., Kujawa, M. J., \& Mahmoud, R. A. (2010). Psychometric evaluation of a patient-rated most troubling symptom scale for depression: findings from a secondary analysis of a clinical trial. Int Clin Psychopharmacol, 5(2), 51-9. doi: 10.1097/YIC.0b013e3283320667.

Pedrotti, J. T., Shane, J., Charles, L., \& Snyder, R. (2021) Positive Psychology: The Scientific and Practical Explorations of Human Strengths, SAGE Publications, In 9781544341750

Totterdell, P., Reynolds, S., Parkinson, B., \& Briner, R. B. (1994). Associations of sleep with everyday mood, minor symptoms and social interaction experience. Sleep, 17(5), 466-75. doi: 10.1093/sleep/17.5.466. 
Journal of Advance Research in Science and Social Science (JARSSC)

Official Publication of Indian Mental Health \& Research Centre

DOI: $10.46523 /$ jarssc. 05.01 .07

Multidisciplinary, Open Access
ISSN: 2582-2004

Volume 05, Issue 01

Triantafillou, S., Saeb, S., Lattie, E. G., Mohr, D. C., \& Kording, K. P. (2019). Relationship Between Sleep Quality and Mood: Ecological Momentary Assessment Study. JMIR mental health, 6(3), e12613. https://doi.org/10.2196/12613

Turvey, C. L., Conwell, Y., Jones, M. P., Phillips, C., Simonsick, E., Pearson, J. L., \& Wallace, R. (2002). Risk factors for late-life suicide: a prospective, community-based study. Am J Geriatr Psychiatry, 10(4), 398-406.

Watson, D. (2002). Positive affectivity: The disposition to experience pleasurable emotional states. In C. R. Snyder \& S. J. Lopez (Eds.), The handbook of positive psychology (pp. 106-119). New York: Oxford University Press.

Watson, D., \& Clark, L. A. (1994). The PANAS-X: Manual for the Positive and Negative Affect Schedule-Expanded Form. Unpublished manuscript, University of Iowa, Iowa City.

Watson, D., \& Naragon-Gainey, K. (2014). Personality, emotions, and the emotional disorders. Clinical Psychological Science, 2, 422-442.

Zimmermann, T. M., Clouth, J., Elosge, M., Heurich, M., Schneider, E., Wilhelm, S., \& Wolfrath, A. (2013). Patient preferences for outcomes of depression treatment in Germany: a choice-based conjoint analysis study. J Affect Disord, 148(2-3), 210-9. doi: 10.1016/j.jad.2012.11.062. 